\title{
Peritoneal Dialysis Catheter Placement Techniques
}

\author{
Mary Buffington*, Adrian Sequeira, Bharat Sachdeva and Kenneth Abreo
}

Nephrology Section, Department of Medicine, LSU Health Sciences Center, Shreveport Louisiana, USA

\begin{abstract}
The success of catheter placement is critically important for the ability to stay on peritoneal dialysis over the long-term. Nephrologists have used percutaneous placement with or without fluoroscopic guidance and placement using peritoneoscopic guidance to place these catheters. Complications can be divided into early, within 14 days, and late complications, those arising more that 14 days after the procedure. The main post-procedure complications are infection, leakage, and obstruction. Results of non-invasive placement have been comparable to surgical placements. The noninvasive technique is simple with minimal intra-operative morbidity, and a post-placement complication rate better than surgical placements. Comparing percutaneously placed catheters to laparoscopically and peritoneoscopically placed catheters shows that the laparoscopic technique has a better one year survival rate. In deciding which technique is best for the patient, it is important to identify advantages of percutaneous placement, such as use of local anesthesia, lower rates of complications, the fact that it is a bedside or office procedure, versus the limitations in that the percutaneous method is not suited for obese patients or those patients likely to have peritoneal adhesions. Peritoneal catheters can be placed in a timely manner without delays associated with surgical scheduling. This offers an added option, both to the neprhologist and the patient and may avoid starting dialysis using a central venous catheter. The placement of peritoneal dialysis catheters by nephrologists has been shown to increase utilization of peritoneal dialysis as a dialysis modality, and this is an important advantage of the procedure.
\end{abstract}

Keywords: Peritoneal, dialysis, catheter, insertion.

\section{INTRODUCTION}

Providing peritoneal access with a minimum of complications is the key to successful peritoneal dialysis. This article reviews the procedures relating to peritoneal dialysis (PD) access placed by interventional nephrologists. The review includes catheter types, pre-procedure evaluation, placement methods, and common complications encountered post-procedure. Peritoneal dialysis is an underutilized mode of dialysis. As of 2007, only 7.2 percent of the dialysis population in the United States was on peritoneal dialysis [1]. Placement of peritoneal dialysis catheters by nephrologists avoids delays associated with surgical placement and risks associated with general anesthesia with comparable rates of complications. These factors can increase the number of patients on peritoneal dialysis. Studies show that catheter placement by interventional nephrologists actually increases utilization of peritoneal dialysis as a dialysis modality within that group's practice [2-4]. However, data from Centers for Medicare and Medicaid Services indicates that only $2.3 \%$ of PD catheters placed in 2007 were placed by nephrologists [5].

\section{TYPES OF PERITONEAL DIALYSIS CATHETERS}

Most PD catheters are constructed out of silicone (majority of catheters); but the Cruz catheter is made of polyurethane. Silicone rubber is less irritating to the peritoneum [6]. Polyurethane catheters are stronger allowing catheters to be thin walled with larger lumens. However,

*Address correspondence to this author at the Nephrology Section, LSU Health Sciences Center, Shreveport, LA 71130, USA; Tel: 318-675-7402; Fax: 318-675-5913; E-mail: mbuffi@lsuhsc.edu they have a tendency to break if alcohol or polyethylene glycol is applied to the catheter [7]. The glue holding the cuff to the polyurethane catheter may fail within 2 years resulting in leaks and infections [8].

The intra-peritoneal segment comes in four basic designs: straight Tenckhoff, coiled Tenckhoff, straight Tenckhoff with silicone discs (Toronto Western Hospital, TWH) and Tfluted catheter (Ash advantage) [8]. The intra-peritoneal segment has been designed to diminish outflow obstruction either by preventing the peritoneal surfaces from occluding the side holes (coiled Tenckhoff) or by preventing omental entrapment (TWH, Ash advantage), tip migration (coiled Tenckhoff) and outward migration of the catheter (Ash advantage). The coiled catheters cause less discomfort by minimizing the jet effect caused by rapid inflow of dialysate. Studies seem to show that coiled catheters do better than straight catheters in terms of minimizing tip migration (drainage failure) and have better catheter survival $[9,10]$.

The extraperitoneal segment has either a Dacron cuff or a disc bead (TWH and Missouri catheters) with or without a Dacron cuff. The cuff induces a local inflammatory response with subsequent fibrosis that serves to anchor the catheter, prevent leaks around the catheter as well as preventing bacterial migration from the exit site or from the peritoneum into the subcutaneous tunnel. Double cuffed catheters minimize exit site, tunnel infections and peritonitis $[6-8,11]$; however, the single cuff catheter can have good results when that cuff is placed in a deep rather than superficial position. In that case, the outcome is comparable to the two cuffed straight Tenckhoff catheters $[12,13]$.

The subcutaneous part (between rectus muscle and exit site) of the extra-peritoneal segment has been generally 
designed to direct the catheter in a lateral or downward direction toward the exit site thereby minimizing exit site infection. There are three basic shapes: straight, swan neck with a $150^{\circ}$ bend and pail handle with two $90^{\circ}$ bends (Cruz catheter) [8]. Studies suggest that there is no difference in exit site infections between the swan neck and straight catheters [14]; however, the swan neck catheter has a lower incidence of cuff extrusion and pericatheter leakage [15]. The swan-neck catheter can be extended using a titanium connector to exit on the chest wall in obese patients, those with abdominal stoma, children with recurrent exit site infections and those in diapers.

\section{PRE-OPERATIVE EVALUATION}

The preoperative assessment includes a history, physical exam and blood work (CBC, blood group, PT/PTT, INR). Previous abdominal surgeries or attempts at catheter placement should raise the question of whether the patient has anatomic barriers to percutaneous placement. Those patients should be referred for laparoscopic placement of the catheter. The physical exam should focus on the presence of abdominal hernias or abdominal wall weakness. Careful attention should be paid to hepato-splenomegaly, enlarged bladder, or pelvic masses caused by fibroids.

The exit site should be selected and marked (Fig. 1). This is done with the patient supine and wearing clothing so as to identify the belt line. The exit site should be above or below the belt line and away from scars. The patient should be observed standing to identify folds of the abdominal wall or sites where pressure maybe applied during daily activity. The exit site should be directed laterally and downward when using a swan-neck catheter or laterally when the catheter does not have a pre-formed bend. It should never be directed in an upward direction because this will increase the risk for exit site infection. The exit site should be easily visualized by the patient. Obese patients or those with stomas or excessive abdominal folds may prefer a pre-sternal catheter with the exit site on the chest.

Holding low molecular weight heparin and warfarin for 24 hours prior to an open surgical technique of catheter placement results in a bleeding rate of only $2 \%$ [16]. PD catheter placement can be safely performed under low dose aspirin therapy $[17,18]$. Screening for nasal carriers of MRSA allows treatment in order to reduce the rate of exit site and tunnel infections [19, 20]. A Foley catheter should be placed the morning of the procedure to prevent retention from incomplete voiding and assist with early detection of inadvertent placement of the PD catheter in the bladder. Bowel evacuation has been recommended [12]. The use of prophylactic antibiotics with a first or second generation cephalosporin reduces the risk of peritonitis and exit site infections $[12,20,21]$. Routine use of vancomycin should be avoided to prevent the development of vancomycin resistant enterococcus (VRE) [12]. The patient should also shower on the morning of the procedure. Abdominal hair should be clipped if required.

\section{PLACEMENT OF THE CATHETER}

Location of Insertion: Paramedian insertion of the deep cuff and ensuring that the deep cuff is tunneled into the rectus muscle prevents catheter leaks. The left side is usually selected for convenience because most operators are right handed. Peristaltic movements cause migration of the catheter into the right upper quadrant, a complication seen in $15-30 \%$ of insertions. Migration is more likely to happen when the catheter tip is positioned in the right iliac fossa $[3,22]$.

Commonly, a site $2-4 \mathrm{~cm}$ below (caudal) or above (cephalad) and left of the umbilicus is selected for catheter insertion [23-28]. The location should be identified and marked prior to starting the case as described above and as shown in Fig. (1). The pubic symphysis has been recommended as a reliable landmark for the ideal location of the catheter tip in the true pelvis [29] and confirmed laparoscopically [30].

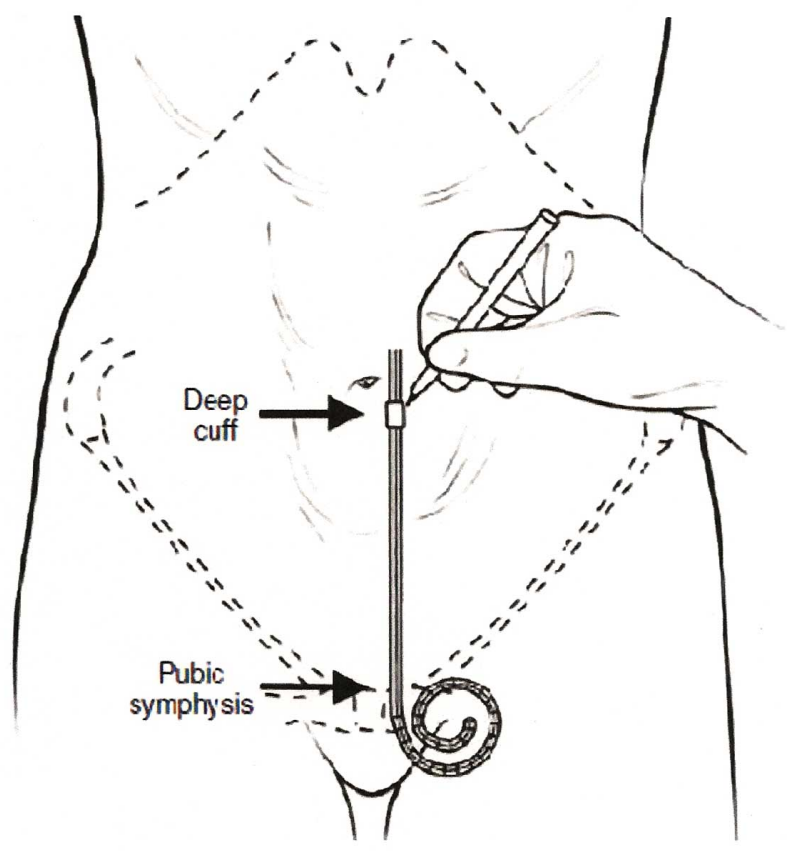

Fig. (1). Location of insertion site. (Reprinted with permission, ref. [33]).

Incision and Blunt Dissection: After infiltrating the skin and underlying tissue with $2 \%$ lidocaine with epinephrine, a horizontal incision $3-4 \mathrm{~cm}$ long is made to expose subcutaneous tissue (obese individuals may need an appropriately longer incision). Blunt dissection of the subcutaneous tissue is done until the shiny anterior rectus sheath is seen and bleeding vessels are ligated or cauterized. The rectus sheath, rectus muscle, and peritoneum are infiltrated with local anesthestic (the needle is aspirated as it is withdrawn to ascertain that the epigastric artery is not in its path).

The above steps are common to the fluoroscopic and peritoneoscopic techniques of catheter placement. The steps unique to each technique are described below.

\section{FLUOROSCOPIC CATHETER INSERTION}

A 22-gauge needle is inserted at an angle of 45 degrees, directed toward the lower pelvis (Fig. 2). It is important that the needle enters the peritoneal cavity $2-3 \mathrm{~cm}$ caudal to (below) the entry into the rectus sheath. This orientation of the catheter entry into the peritoneal cavity would help 
minimize catheter migration. The location of the needle within the peritoneal cavity is confirmed by injecting 3-5 cc of contrast. A smudge at catheter tip (extra peritoneal tip) or a scaffolding pattern (bowel lumen pattern) would require replacement of the needle. A micropuncture (0.018 inch) wire is then inserted through the needle and its course noted under fluoroscopy (Fig. 3). After confirmation of its position in the lower pelvis, a 5-French catheter is inserted over the wire. Contrast can again be injected through the catheter to confirm its position (Fig. 4). Perforation of the bowel with the micro-puncture needle has minimal risk of peritonitis. If perforation is suspected the best option is to abandon the procedure and administer broad-spectrum antibiotics for 24 hours.

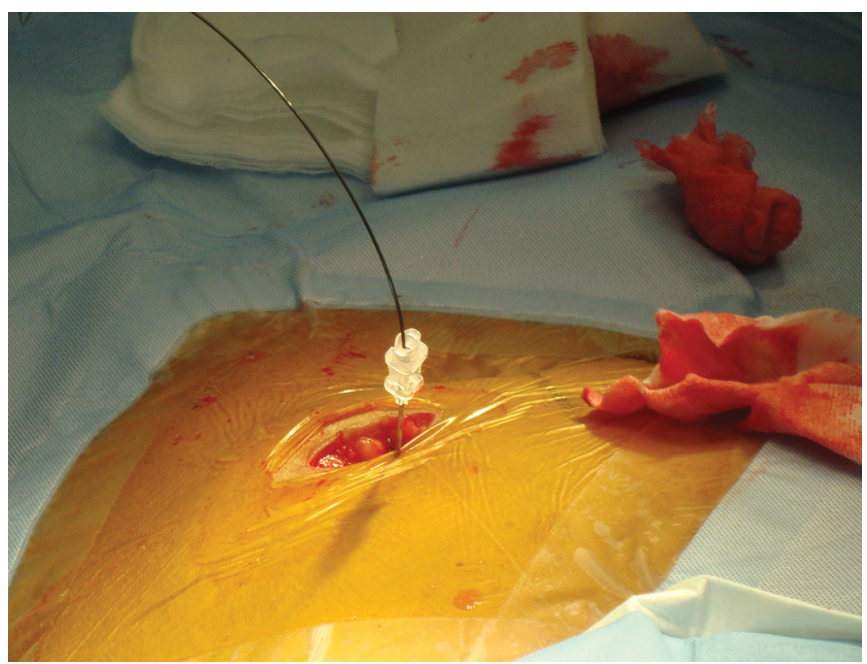

Fig. (2). A needle is inserted through the rectus muscle and guide wire is then inserted through the needle.

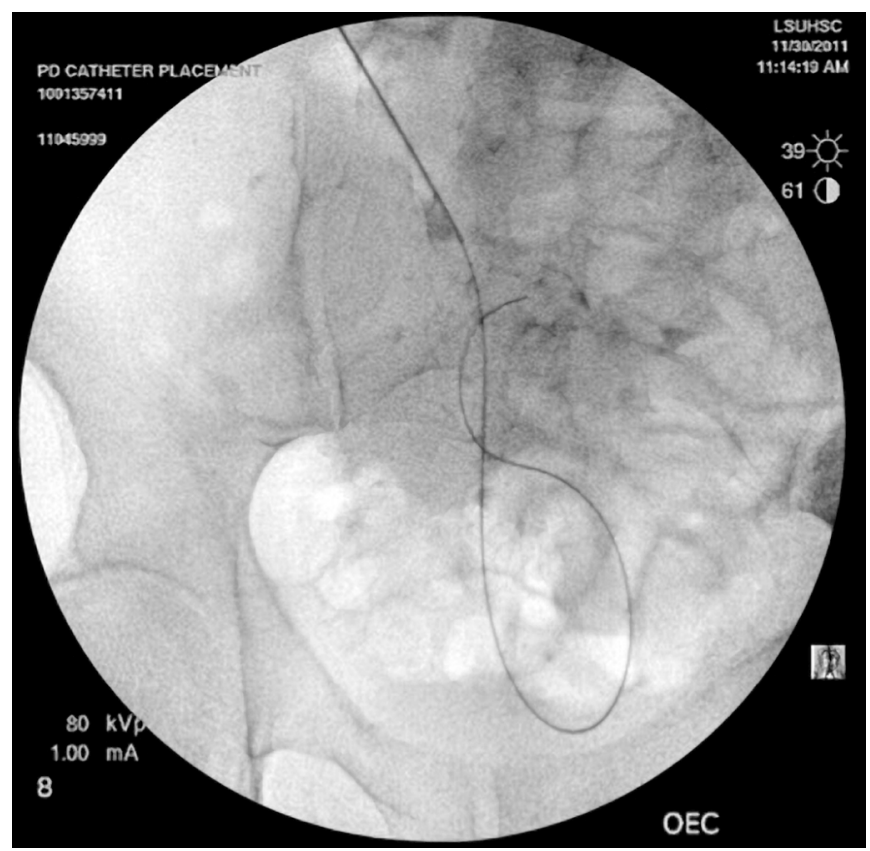

Fig. (3). Course of the wire introduced through the needle noted under fluoroscopy.

Use of a blunt tipped $18 \mathrm{~g}$ needle instead of micropuncture needle to access the peritoneum minimizes the risk of bowel perforation [23]. Besides prevention of perforation, a pop and give can be felt on entry into the peritoneal space with a blunt tipped needle. In addition, a larger guide wire (0.035-inch) can be passed into the abdomen precluding the use of a micro-puncture needle and wire.

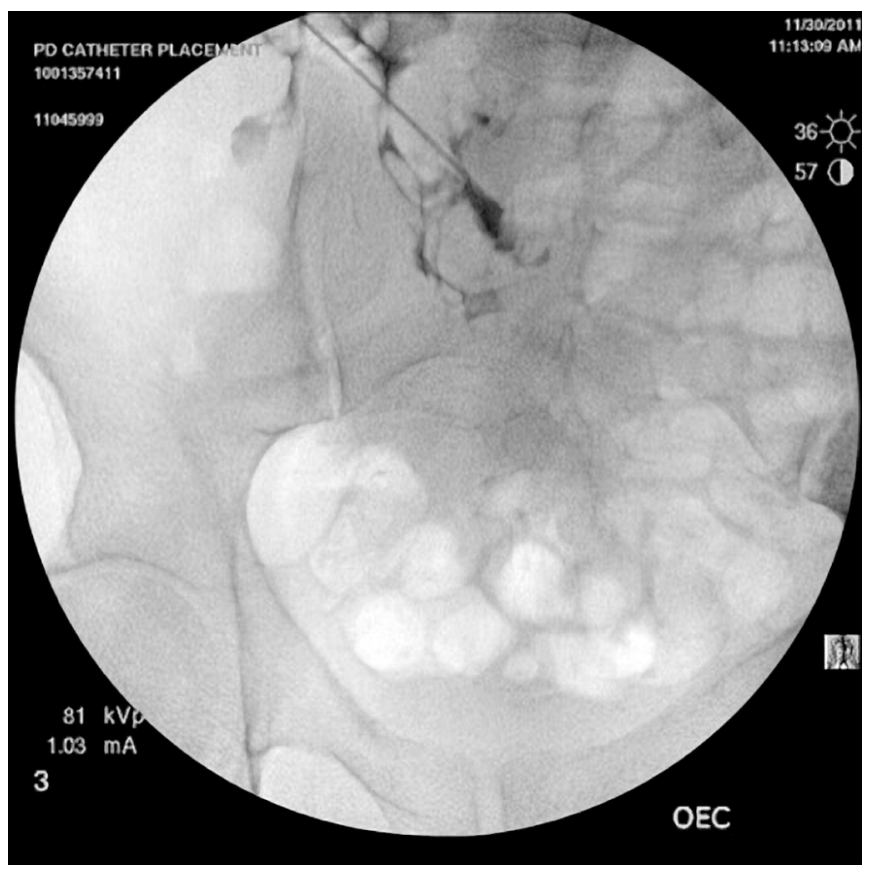

Fig. (4). Contrast injected outlines the bowel wall.

Gaining access into the peritoneal cavity can also be undertaken under real time ultrasound guidance [26, 27]. Ultrasound measures the distance from the skin to the peritoneal cavity and color Doppler can locate the epigastric and hypogastric vessels, minimizing the risk of bleeding [26].

The 0.035-inch glide wire is then passed through the 5 -French catheter until sufficient wire forms a comfortable curve in the pelvis (Fig. 3). Rectus sheath, rectus muscle, deep fascia and the peritoneal membrane are dilated sequentially using $10 \mathrm{~F}$ to $17 \mathrm{~F}$ dilators over the guide wire (Figs. 5, 6). The final 18-French dilator with a peel-away sheath is placed into the peritoneal cavity. After removing the dilator in the sheath (wire to be left in place if placement of catheter is done over wire); the PD catheter is then advanced over the glide wire. The radio-opaque line on the PD catheter allows for confirmation of its position in the lower pelvis (Fig. 7). The catheter can be rotated and moved at this point to ensure that the "pigtail" portion is located in the pelvis. Contrast can be injected into the catheter for better visualization. One liter of PD fluid is infused into the abdomen through the catheter to evaluate its function. Inflow should be rapid and pain free and outflow should be a fast drip or stream that increases with deep inspiration. The catheter can be repositioned using a metal stylet until optimum function is achieved.

The deep cuff is buried in the rectus muscle with the use of the cuff pusher as the catheter is stabilized on the stylet [25]. When placement is done over wire, a set of non traumatic forceps are used to pass the cuff beyond the rectus sheath, the peel away sheath is withdrawn slowly ensuring that the cuff stays within the rectus muscle [26, 27]. Holding the cuff in place with the blunt forceps, when the peel-away 
sheath is removed, helps prevent its dislodgement. Some operators pass an absorbable suture through the deep cuff and the outer rectus sheath and subcutaneous tissues and tie the suture once the cuff is buried in the rectus muscle to anchor the cuff $[24,28]$.

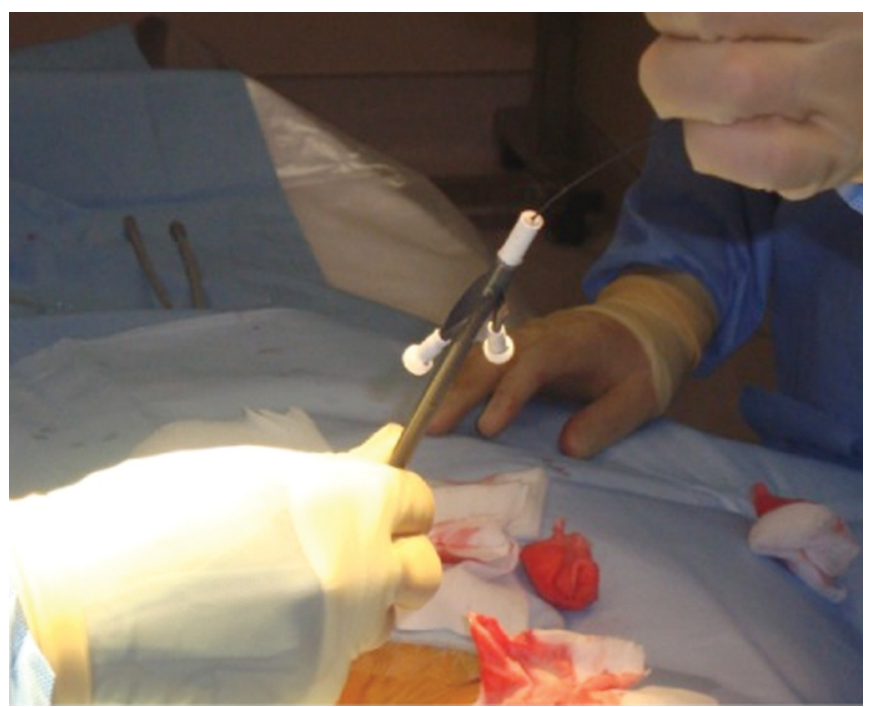

Fig. (5). Dilators from $10 \mathrm{Fr}$ to $17 \mathrm{Fr}$ are advanced sequentially over the guide wire.

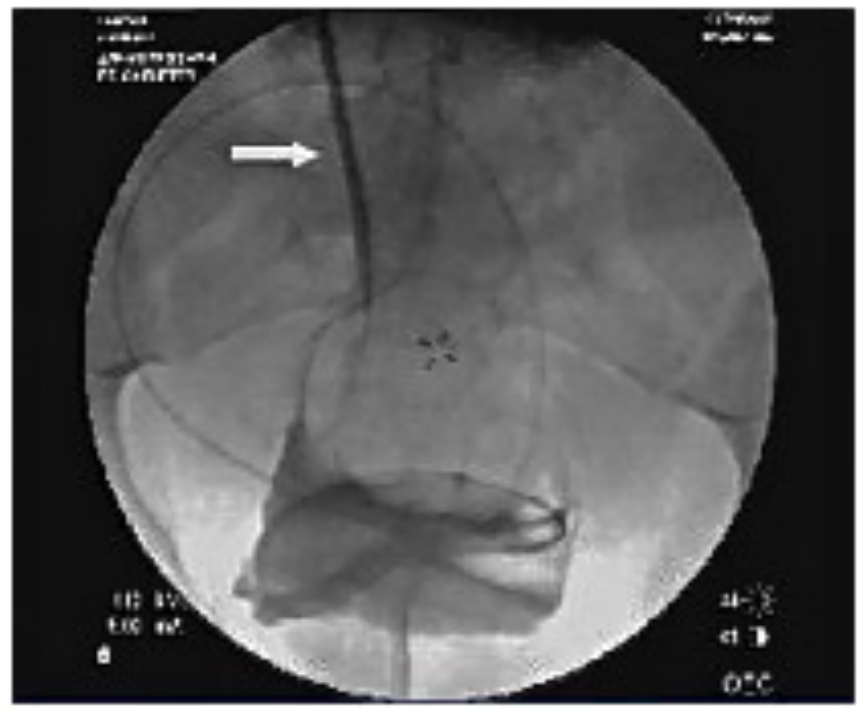

Fig. (6). Fluoroscopic view of a dilator being advanced over a guidewire.

\section{PERITONEOSCOPIC CATHETER PLACEMENT:}

Peritoneoscopic placement is done under local anesthesia with a single puncture site for the Quill ${ }^{\mathbb{B}}$ Catheter Guide [31] through which the scope is inserted and later becomes the pathway for the catheter insertion. Once the rectus sheath is identified, more lidocaine is infiltrated into the rectus sheath and muscle. The patient is asked to tighten his/her abdominal muscles prior to inserting the Quill ${ }^{\circledR}$ catheter guide assembly. Just as with the fluoroscopic catheter placement, this step is important to orient the catheter towards the pelvis. The catheter guide assembly should enter the rectus sheath at a $30 \%$ angle and directed towards the coccyx. Peritoneal entry should be felt with the giveaway sensation at entry into the peritoneal cavity.

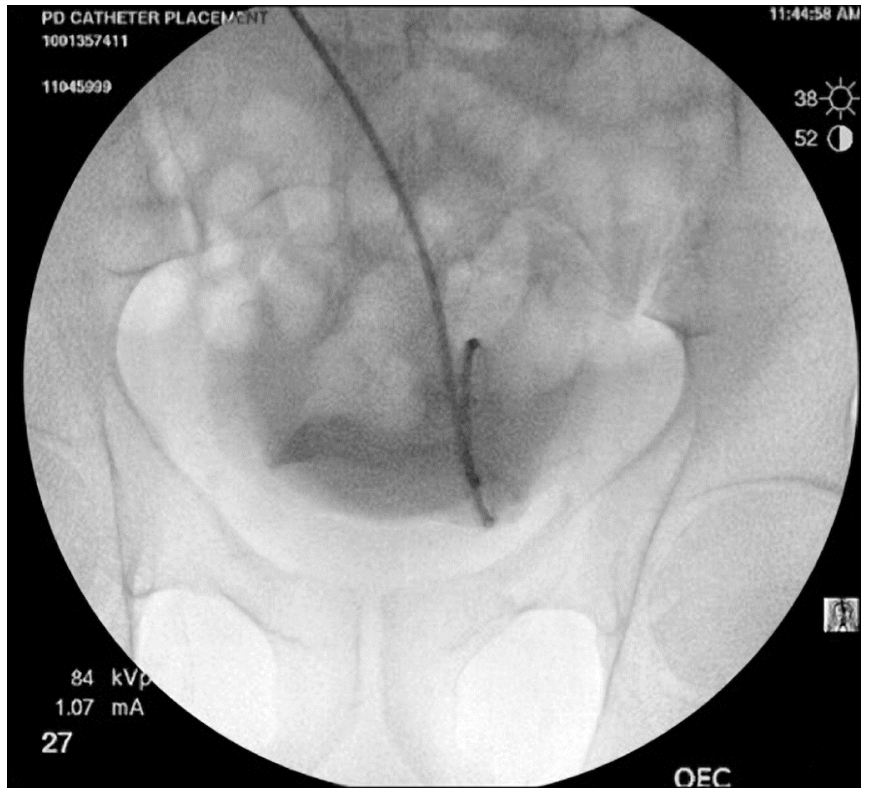

Fig. (7). Contrast injected into the PD catheter for better visualization.

Bowel perforation has been described in $<1 \%$ of trocar insertions into the peritoneal cavity. Insufflating peritoneal cavity with gas prior to trocar insertion can further decrease this complication. A blunt tip needle or Veress insufflation needle is used to access the peritoneal cavity and air is injected (the patient is placed in Trendelenburg position and approximately $700-1200 \mathrm{cc}$ of air, depending on patient size) prior to tocar use $[23,32]$.

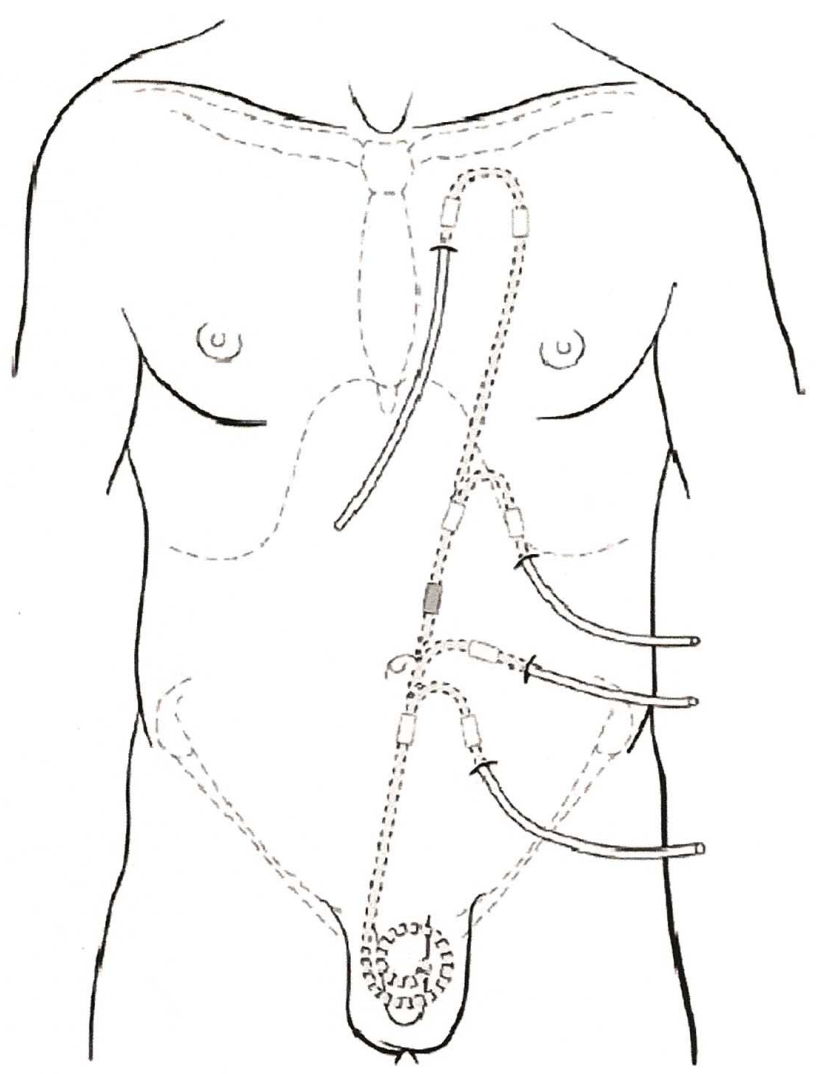

Fig. (8). Tenckhoff catheter modifications for a variety of exit sites. (Reprinted with permission, ref. [33]). 
The Y-TEC ${ }^{\circledR}$ scope, modified optic scope for peritoneoscopic catheter insertion, is passed into the cannula, locked, the light guide snapped on to the scope and location within the peritoneum is confirmed. Every time the scope is passed into the cannula it is locked prior to visualizing the peritoneal cavity.

The Y-TEC ${ }^{\circledR}$ System itself is composed of reusable instruments $(2.2 \mathrm{~mm}$ diameter endoscope, fiberoptic light guide, sterilization tray, and a fiberoptic light source) and a choice of two disposable catheter implantation kits, referred to as "pacs" by Y-Tec. This kit and procedure can be used to implant almost all PD catheters including the Flex-Neck ${ }^{\circledR}$, Swan-Neck ${ }^{\mathrm{TM}}$, and conventional catheters. (The Toronto Western $^{\mathrm{TM}}$ and Missouri Swan-Neck ${ }^{\mathrm{TM}}$ catheters cannot be implanted with this technique).

Peritoneoscopic examination of the peritoneal cavity ensures placement of the trocar assembly into the peritoneal cavity. If the bowel surface is not visualized or the image is all white, the scope is withdrawn and the peritoneal cavity is viewed again. It is very important that bowel surface be seen and movement seen in conjunction with respiration, to verify that the scope is within the peritoneum. If there is no movement the scope is withdrawn slowly while asking the patient to take deep breaths. Once the placement is confirmed to be in the peritoneal cavity, the scope is withdrawn and air injected (if not done earlier). The scope is replaced and locked, the light source is attached, the tip of the scope positioned (with the Quill assembly) in the desired location. After visualizing adhesions and omental folds, the best location for the catheter is identified. The Quill ${ }^{\circledR}$ Guide Assembly is advanced fully into the peritoneum so that the distal end is at the lower part of the inguinal area. The scope is then withdrawn and the tape holding the Quill ${ }^{\circledR}$ Guide to the cannula is removed with a hemostat.

The outer end of the Quill sheath is secured using a hemostat $2 \mathrm{~mm}$ above the shoulder of the Quill Catheter guide and the cannula is removed with a slight twisting/rotating motion. The Quill Catheter guide remains in the same location where the scope had directed it. Dilators are inserted into the Quill guide starting with the smaller 4.8 $\mathrm{mm}$ after lubrication with gel and followed by the $6.4 \mathrm{~mm}$ dilator. The catheter is prepared for insertion by placing it on a stylette with sterile gel or saline with its tip even with the catheter tip. Catheter orientation (marked on catheter with a white stripe) should be aligned so as the catheter is not twisted or rotated on its axis. The catheter with stylette is inserted carefully into the Quill ${ }^{\circledR}$ Guide. Catheter placed on the left should have the white stripe on catheter at $12 \mathrm{o}$ ' clock position and at 6 o'clock when placed on right. It is important to follow the Quill ${ }^{\circledR}$ Guide through the rectus muscle and into the desired location in the peritoneum. The catheter is advanced through the Quill ${ }^{\circledR}$ Guide and holding the outer end of the stylette the catheter is pushed off the stylette into the peritoneal cavity. The tip of the stylette should be kept within the abdomen to help place the catheter cuff through the rectus. The operater should make certain that the catheter is not doubled on itself, kinked, or twisted. The Y-TEC ${ }^{\circledR}$ Cuff Implantor ${ }^{\circledR}$ is positioned parallel with and over the catheter between the two cuffs. The catheter and Cuff Implantor ${ }^{\circledR}$ are advanced simultaneously $1 \mathrm{~cm}$ to both dilate the Quill ${ }^{\circledR}$ Guide (and rectus) and advance the cuff into the rectus muscle. The Quill ${ }^{\circledR}$ Guide is retracted by folding it on a hemostat, followed by removal of the stylette [23, 31].

Exit Site and Superficial Cuff (Both Techniques): The location of the exit site should be determined as described above. The swan neck catheter is best suited for the location of the exit site in the lower abdomen and the straight catheter for exit sites on the upper abdomen. Patients who are obese, have abdominal stomas, are incontinent of urine or feces, and who desire to take a deep tub bath would benefit from an extended catheter system that would allow for an exit site located in the upper abdomen or chest (Fig. 8) [33, 34].

Using local anesthesia, a stab wound is made and a tunneling device or a Kelly clamp is inserted into the stab incision and tunneled into the subcutaneous tissues to engage or grasp the catheter tip. The catheter is pulled through the tunnel and out of the exit site [23, 25, 26].

Wound Closure: The subcutaneous tissue of the primary incision is closed with absorbable sutures and the skin is closed with non-absorbable sutures [25]. The exit site should not be sutured [24], as this may cause an exit site infection. The two cuffs provide sufficient anchoring to prevent the catheter from falling out. The catheter is flushed with saline and $7000 \mathrm{U}$ of heparin are instilled in the catheter after the connectors are attached.

\section{POST-OPERATIVE MANAGEMENT}

The catheter can be capped after the peritoneal cavity is flushed with 500 to $1500 \mathrm{ml}$ of heparinized dialysate until the effluent becomes clear [35]. The patient's vital signs are then monitored to assure stability. Some centers perform the procedure on an outpatient basis with the patient returning home 4-6 hours post-procedure, whereas others prefer to observe the patient overnight [36]. The exit site and surgical incision are covered with sterile gauze and a non-occlusive dressing. The patient is advised to minimize contact with the catheter and surgical incisions until the wounds have healed and the tunnel has matured. The catheter is taped securely and remains immobile when not in use. After discharge, a PD nurse should evaluate the patient each week and perform a low volume exchange with 1 liter of $1.5 \%$ dextrose (Dianeal) to test the function of the catheter and educate the patient about PD and appropriate catheter use. Full volume exchanges can begin in 2-3 weeks after catheter placement [35]. Patients should avoid baths that immerse the exit site and swimming in lakes, rivers or public baths [35].

Beginning PD before the deep cuff matures increases the risk of leakage. If the patient requires dialysis immediately following the procedure, low volume exchanges are preferred. This could spare the patient the need for a central venous catheter. However, the patient should remain supine during catheter use to avoid pericatheter leakage [35].

\section{COMPLICATIONS OF CATHETER PLACEMENT}

The percutaneous method of catheter placement has low complication rates when performed by experienced operators (Table 1). The most common peri-operative complications of catheter placement are dialysate leakage, infection, and catheter drainage failure. Bowel and bladder perforation along with bleeding and hematoma are rare complications. 
Catheter related infection includes exit site infection and peritonitis. Only those instances occurring soon after catheter placement should be attributed to the procedure. Studies vary with regard to the definition of an early infection, with the time period ranging from 2 weeks or longer. Arguably, an infection occurring more that 2 weeks after a procedure should not be attributed to the placement. An exit site infection has induration, erythema, or drainage from the site where the catheter exits the skin. This is one of the most frequent complications of PD catheters in general. Directing the exit site laterally or inferiorly reduces the occurrence of infection. Also, use of antibiotic cream at the exit site--

Table 1. Summary of Complications of Catheter Placement

\begin{tabular}{|c|c|c|c|c|c|c|c|}
\hline Source & No of Catheters & Infection & Drainage Problem & Migration & Leak & Perf. & Success \\
\hline \multicolumn{8}{|c|}{ Fluoroscopy/Percutaneous } \\
\hline Moon [37] & $\begin{array}{l}134 \text { caths/ } \\
114 \text { pts }\end{array}$ & Early peritonitis $2.2 \%$ & $1.5 \%$ & $1.5 \%$ & $3 \%$ & 0 & $\begin{array}{l}1 \text { yr. } 80 \% \\
2 \text { yr. } 74.9 \% \\
5 \text { yr } 71.1 \%\end{array}$ \\
\hline Zaman [25] & 36 caths & 0 & $2.9 \%$ & $3 \%$ & $3 \%$ & 0 & $\begin{array}{l}1 \mathrm{~m} .100 \% \\
3 \mathrm{~m} .97 \% \\
1 \mathrm{yr} .89 \%\end{array}$ \\
\hline Vaux [27] & 209 & $\begin{array}{l}\text { Early exit site } 6.5 \% \text {; } \\
\text { Early peritonitis } 1.5 \%\end{array}$ & $5 \%$ & $7 \%$ & $5 \%$ & 0 & $\begin{array}{l}1 \text { yr } 77 \% \\
2 \text { yr } 61 \% \\
5 \text { yr } 31 \%\end{array}$ \\
\hline Maya [26] & 32 & 0 & & $3 \%$ & 0 & $3 \%$ & 27 mos. $90.6 \%$ \\
\hline Jacob [23] & 45 & Total peritonitis $7 \%$ & $13.3 \%$ & $11 \%$ & $9 \%$ & $4.4 \%$ & \\
\hline \multicolumn{8}{|l|}{ Peritoneoscope } \\
\hline Goh [3] & 91 & 1 in $93.7 \mathrm{pt}$ months & $17.6 \%$ & $9.8 \%$ & & & $1 \mathrm{yr} 86.4 \%$ \\
\hline Gadallah [38] & 76 & $\begin{array}{l}\text { Early peritonitis } 2.6 \% \\
\text { Late infection } 48.7 \%\end{array}$ & $\begin{array}{l}\text { Early } 7.9 \% \\
\text { Late } 7.9 \%\end{array}$ & & $\begin{array}{l}\text { Early } \\
1.3 \%\end{array}$ & $\begin{array}{l}\text { Colon } \\
1.3 \%\end{array}$ & $\begin{array}{l}1 \text { yr } 77.5 \% \\
2 \text { yr } 63 \% \\
3 \text { yr } 51.3 \%\end{array}$ \\
\hline \multicolumn{8}{|l|}{ Percutaneous } \\
\hline Henderson [39] & 283 & $\begin{array}{l}\text { Early peritonitis } 4 \% \text { ( } 30 \\
\text { days) }\end{array}$ & $21 \%$ & & $6 \%$ & & $\begin{array}{l}1 \mathrm{mo} 87 \% \\
6 \mathrm{mo.} 83 \%\end{array}$ \\
\hline Perakis [40] & 86 & $\begin{array}{l}\text { Early peritonitis } 4.3 \text { per } 1000 \\
\text { pt mo.; early exit site } 1.6 \text { per } \\
1000 \text { pt mo. }\end{array}$ & $\begin{array}{l}23.2 \% \\
(10.7 \text { per } 1000 \\
\text { pt mo })\end{array}$ & $15.1 \%$ & $23 \%$ & 0 & $\begin{array}{l}1 \text { yr } 89.5 \% \\
2 \text { yr } 83.7 \% \\
3 \text { yr } 83.7 \%\end{array}$ \\
\hline Ozener [41] & 133 & $\begin{array}{l}\text { Early cath related } \\
\text { Infection 3\% }\end{array}$ & $11.2 \%$ & $8.2 \%$ & $8.3 \%$ & 0 & $\begin{array}{l}1 \mathrm{yr} 90 \% \\
2 \mathrm{yr} 82 \%\end{array}$ \\
\hline \multicolumn{8}{|c|}{ Surgery/Laparoscopy } \\
\hline Henderson [39] & 150 & $\begin{array}{l}\text { Early peritonitis } 13 \% \text { (30 } \\
\text { days) }\end{array}$ & $23 \%$ & & $10 \%$ & & \\
\hline Maio [42] & 100 & & $6 \%$ & $6 \%$ & $13 \%$ & & $\begin{array}{l}1 \text { yr } 97 \% \\
2 \text { yr } 95 \% \\
3 \text { yr } 91 \%\end{array}$ \\
\hline Perakis [40] & 84 & $\begin{array}{l}\text { Early peritonitis } 10.1 \text { per } \\
1000 \text { pt mo; early exit site } 6.3 \\
\text { per } 1000 \text { pt mo }\end{array}$ & $\begin{array}{l}29.7 \% \\
(7.9 \text { per } 1000 \\
\text { Pt mo })\end{array}$ & $28.6 \%$ & $13 \%$ & & $\begin{array}{l}1 \text { yr } 91.1 \% \\
2 \text { yr } 80.7 \% \\
3 \text { yr } 73.2 \%\end{array}$ \\
\hline Crabtree [30] & 200 & & $0.5 \%$ & & $2 \%$ & & \\
\hline Keshvari [43] & 175 & & $8.5 \%$ & $1.7 \%$ & $7.4 \%$ & 0 & $\begin{array}{l}1 \text { yr } 92.7 \% \\
2 \text { yr } 91.3 \%\end{array}$ \\
\hline \multicolumn{8}{|c|}{ Surgery/Dissection } \\
\hline Ozener [41] & 82 & $\begin{array}{l}\text { Early cath related } \\
\text { Infection } 2 \%\end{array}$ & $19.5 \%$ & $13.4 \%$ & $6.1 \%$ & & $\begin{array}{l}1 \text { yr } 73 \% \\
2 \text { yr } 60 \%\end{array}$ \\
\hline Gadallah [38] & 72 & $\begin{array}{l}\text { Early Peritonitis } 12.5 \% \\
\text { Late Infection } 48.6 \%\end{array}$ & $\begin{array}{l}\text { Early } 8.3 \% \\
\text { Late } 11.1 \%\end{array}$ & & $\begin{array}{l}\text { Early } \\
11.1 \%\end{array}$ & $\begin{array}{l}\text { Bladder } \\
1.4 \%\end{array}$ & $\begin{array}{l}1 \text { yr } 62.5 \% \\
2 \text { yr } 41.5 \% \\
3 \text { yr } 36 \%\end{array}$ \\
\hline
\end{tabular}


either mupirocin [44] to prevent gram positive infections or gentamicin [45] to prevent gram positive and gram negative infections -- reduces the occurrence of exit site infections and peritonitis. Studies have reported a rate of early exit site infections ranging from 0 to $6.5 \%$ using the percutaneous method [25-27]. Modifying the swan-neck catheter to a presternal exit site location has shown an increase in access survival up to $95 \%$ at 2 years and also a decrease in peritonitis and exit site infection [46]. Prophylactic antibiotics can prevent infection within the first 30 days of catheter insertion. Early peritonitis occurred in $1.5 \%$ to $4 \%$ of studies [27, 37-39].

Leakage of dialysate occurs when the deep cuff either is displaced or does not form a fibrotic reaction within the rectus muscle. Treatment of leakage involves resting the peritoneum for 2 days to 3 weeks while the patient is temporarily on hemodialysis or using low volume exchanges, preferably with the patient in supine position. Leakage occurred in $3 \%$ to $8 \%$ of percutaneous placements, with one study showing a $23 \%$ leakage rate (see Table 1).

Catheter dysfunction entails drainage problems due to migration of the catheter, omental wrapping, or obstruction. Placing the catheter by the percutaneous method even using fluoroscopic guidance can result in obstruction by omentum or adhesions. The laparoscopic technique offers an advantage in this regard because the omentum in the pelvis can be tacked to the abdominal wall or removed and adhesions can be lysed. Migration of the catheter tip is caused by peristaltic movement of the bowel that moves the catheter tip into the right upper quadrant. One report noted that placement of the catheter on the right side of the abdomen with the tip in the left iliac fossa can reduce the incidence of catheter migration [22]. With migration, the dialysate will easily fill the peritoneum but will not drain. This has occurred in up to $15 \%$ of percutaneous procedures and up to $28 \%$ in laparoscopic procedures [40]. Migration can be related to constipation, and initial treatment should be laxatives to stimulate the bowel. Other treatments for migration are fluoroscopic manipulation, catheter replacement, or surgical salvage procedures [47]. Some research has shown that the swan neck catheter design reduces the incidence of tip migration [12]. Inflow dysfunction is likely related to fibrin or clot in the catheter. This can be treated with forceful infusion of dialysate or thrombolytics.

Bowel and bladder perforations are very rare with a number of studies reporting no occurrences. With the percutaneous method, it is possible to perforate the bowel with the micro-puncture needle. This will be discovered immediately and in this instance, the needle should be withdrawn and the patient given broad spectrum antibiotics intravenously overnight. If the patient remains afebrile, the procedure can be attempted again the next day.

Hematomas and bleeding can occur when the epigastric vessels are perforated. Using ultrasound to visualize these vessels significantly reduces the risk of this complication.

\section{COMPARISON WITH SURGICAL TECHNIQUES}

Both laparoscopic and percutaneous procedures have low complication rates when performed by experienced operators. Patients should be referred for laparoscopic catheter placement when they are obese, have had previous abdominal surgery or have had repeated episodes of peritonitis that would cause adhesions. Some have argued that comparing complication rates between the two procedures is flawed because there is a selection bias in favor of less challenging subjects for the percutaneous approach. The results of the laparoscopic procedure should be viewed in light of the fact that in some studies the laparoscopic subjects are more challenging [48]. Overall, the complication rate is lower for the percutaneous method. The one year survival rate of catheters is lowest for catheters placed surgically by the dissection method, but highest for catheters placed by laparoscopic method. The one year survival for laparoscopic placement is slightly better than that of the percutaneous method (Table 1).

\section{CONCLUSION}

Patients who are obese, with a history of abdominal surgery or with a history of repeated episodes of peritonitis should be referred to a capable surgeon for the laparoscopic placement of the catheter. For patients without these factors, percutaneous placement of peritoneal dialysis catheters by interventional nephrologists should be attempted. The complication rates for the percutaneous method are similar to those of laparoscopic procedures. This review summarizes the catheter types, pre-procedure work-up, catheter placement technique, post-procedure care and complications. Additionally, having an interventional nephrologist involved in the placement of PD catheters increases utilization of this modality of dialysis.

\section{ACKNOWLEDGEMENT}

Declared none.

\section{CONFLICT OF INTEREST}

Declared none.

\section{REFERENCES}

[1] US Renal Data System, USRDS 2009 Annual Data Report: Atlas of chronic kidney disease and end-stage renal disease in the United States, National Institutes of Health, National Institute of Diabetes and Digestive and Kidney Diseases, Bethesda, MD, 2009. The data reported here have been supplied by the United States Renal Data System (USRDS). The interpretation and reporting of these data are the responsibility of the authors and in no way should be seen as an official policy or interpretation of the US government.

[2] Asif A, Pflederer TA, Vieira CF, Diego J, Roth D, Agarwal A. Does catheter insertion by nephrologists improve peritoneal dialysis utilization? A multicenter analysis. Semin Dial 2005; 18: 157-60.

[3] Goh BL, Ganeshadeva YM, Chew SE, Dalimi MS. Does peritoneal dialysis catheter insertion by interventional nephrologists enhance peritoneal dialysis penetration? Semin Dial 2008; 21: 561-6.

[4] Asif A. Peritoneal dialysis underutilization: the impact of an interventional nephrology peritoneal dialysis access program. Semin Dial 2003; 16: 266-71.

[5] Crabtree JH. Who should place peritoneal dialysis catheters? Perit Dialy Int 2010; 30: 142-50.

[6] Aquila RD, Chiaramonte S, Rodighiero MP, et al. Rational choice of peritoneal dialysis catheter. Perit Dial Int 2007; 27: S119-25.

[7] Gokal R, Alexander S, Ash S, et al. Peritoneal catheters and exit site practice: toward optimum peritoneal access. Perit Dial Int 1998; 18: 1133.

[8] Ash SR. Chronic peritoneal dialysis catheters: overview of design, placement and removal procedures. Semin Dial 2003; 16: 323-34. 
[9] Ates k, Karatan O, Erturk S, et al. Comparison between straight single cuff and curled double cuff catheters in patients on continuous ambulatory peritoneal dialysis. Nephrol Dial Transplant 1996; 11:914.

[10] Nielsen PK, Hemmingsen C, Friis SU, Ladefoged J, Olgaard K. Comparison of straight and curled Tenckhoff peritoneal dialysis catheters implanted by percutaneous technique: a prospective randomized study. Perit Dial Int 1995; 15: 18-21.

[11] Thodis E, Passadakis P, Lyrantzopooulos N, Panagoutsos S, Vargemezis V, Oreopoulos D. Peritoneal catheters and related infections. Int Urol Nephrol 2005; 37: 379- 93.

[12] Flanigan M, Gokal R. Peritoneal catheters and exit site practices toward optimum peritoneal access: a review of current developments. Perit Dial Int 2005; 25: 132-9.

[13] Eklund BH, Honkanen EO, Kyllonen LE, Salmela K, Kala AR. Peritoneal dialysis access: prospective randomized comparison of single cuff and double cuff straight Tenckhoff catheters. Nephrol Dial Transplant 1997; 12: 2664-6.

[14] Eklund BH, Honkanen EO, Kyllonen LE. Peritoneal dialysis access: prospective randomized comparison of the Swan Neck and Tenckhoff Catheters. Perit Dial Int 1995; 15: 353-6.

[15] Hwang T-L, Huang CC. Comparison of Swan Neck catheter with Tenckhoff catheter for CAPD. Adv Perit Dial 1994; 10: 203-5.

[16] Mital S, Fried LF, Piraino B. Bleeding complications associated with peritoneal catheter insertion. Perit Dial Int 2004; 24 : 478-80.

[17] Shpitz B, Plotkin E, Spindel Z, et al. Should aspirin therapy be withheld before insertion and/or removal of a permanent peritoneal dialysis catheter? Am Surg 2002; 68: 762-4

[18] O'Connor SD, Taylor AJ, Williams EC, Winter TC. Coagulation concepts update. Am J Roentgenol 2009; 193: 1656-64.

[19] Mupirocin study group. Nasal mupirocin prevents Staphylococcus aureaus exit site infection during peritoneal dialysis. J Am Soc Nephrol 1996; 7: 2403-8

[20] Bonifati C, Pansini F, Torres DD, Navaneethan SD, Craig JC, Strippoli GF. Antimicrobial agents and catheter-related interventions to prevent peritonitis in peritoneal dialysis: using evidence in the context of clinical practice. Int J Artif Organs 2006; 29: 41-9.

[21] Wikdahl AM, Engman U, Stegmayr BG, Sorenssen JG. One dose cefuroxime i.v. and i.p reduces microbial growth in PD patients after catheter insertion. Nephrol Dial Transplant 1997; 12: 157-60.

[22] Twardowski ZJ, Nolph KD, Khanna R, Prowant BF, Ryan LP, Nichols $\mathrm{K}$. The need for a "swan neck" permanently bent, arcuate peritoneal dialysis catheter. Perit Dial Bull 1985; 5: 219-23.

[23] Jacobs IG, Gray RR, Elliott DS, Grosman H. Radiologic placement of peritoneal dialysis catheters: preliminary experience. Radiology 1992; 182: $251-5$.

[24] Savader SJ, Geschwind JF, Lund GB, Scheel PJ. Percutaneous radiological placement of peritoneal dialysis catheters: long-term results. J Vasc Interv Radiol 2000; 11: 965-70.

[25] Zaman F, Pervez A, Atray NK, Murphy S, Work J, Abreo KD. Fluoroscopically-assisted placement of peritoneal dialysis catheters by nephrologists. Semin Dial 2005; 18: 247-51.

[26] Maya I. Ultrasound/fluoroscopy-assisted placement of peritoneal dialysis catheters. Semin Dial 2007; 20: 611-5.

[27] Vaux EC, Torrie PH, Barker LC, Naik RB, Gibson MR. Percutaneous fluoroscopically guided placement of peritoneal dialysis catheters: A 10-year experience. Semin Dial 2008; 21: 459-65.

[28] Rosenthal MA, Yang PS, Liu IA, et al. Comparison of outcomes of peritoneal dialysis catheters placed by the fluoroscopically guided percutaneous method versus directly visualized surgical method. J Vasc Interv Radiol 2008; 19: 1202-7.
[29] Twardowski ZJ. Peritoneal catheter placement and management. In: Massry SG, Suki WN, Eds. Therapy of Renal Disease and Related Disorders. Kluwer Academic: 8wDordrecht 1997; pp 953-79.

[30] Crabtree JH, Fishman A. A laparoscopic method for optimal peritoneal dialysis access. Am Surg 2005; 71: 135-43.

[31] Y-Tec Instructions: Laparoscopic \& Percutaneoscopic Placement of Peritoneal Dialysis Catheters, http:/www.medigroupinc.com/ytecinstructions.pdf

[32] Asif A, Tawakol J, Khan T, et al. Modification of the peritoneoscopic technique of peritoneal dialysis catheter insertion: experience of an interventional nephrology program. Semin Dial 2004; 17: 171-3.

[33] Crabtree JH. Selected best demonstrated practices in peritoneal dialysis access. Kidney Internat2006; 70: S27-S37.

[34] Sreenarasimhaiah VP, Margassery SK, Martin KJ, Bander SJ. Percutaneous technique of presternal peritoneal dialysis catheter placement. Semin Dial 2004; 17: 407-10.

[35] Gokol R, Ash SR, Helfrich B, et al. Peritoneal catheters and exit-site practices: toward optimum peritoneal access. Perit Dial Int 1993; 13: 29-39.

[36] Maya ID. Ambulatory setting for peritoneal dialysis catheter placement. Semin Dial 2008; 21: 457-8

[37] Moon J-Y, Sebin S, Jung K-H, et al. Fluoroscopically guided peritoneal dialysis catheter placement: long-term results from a single center. Perit Dial Int 2008; 28: 163-9.

[38] Gadallah MF, Pervez A, El-Shahawy MA, et al. Peritoneoscopic versus surgical placement of peritoneal dialysis catheters: a prospective randomized study on outcome. Am J Kidney Dis 1999; 33: 118-22.

[39] Henderson S, Brown E, Levy J. Safety and efficacy of percutaneous insertion of peritoneal dialysis catheters under sedation and local anaesthetic. Nephrol Dial Transplant 2009; 24: 3499-504.

[40] Perakis KE, Stylianou KG, Kyriazis JP. Long-term complication rates and survival of peritoneal dialysis catheters: the role of percutaneous versus surgical placement. Semin Dial 2009; 22: 569-75.

[41] Ozener C, Bihorac A, Akoglu. Technical survival of CAPD catheters: comparison between percutaneous and conventional surgical placement techniques. Nephrol Dial Transplant 2001; 16: 1893-9.

[42] Maio R, Figueiredo N, Costa P, Laparoscopic placement of Tenckhoff catheters for peritoneal dialysis: a safe, effective, and reproducible procedure. Perit Dial Int 2008; 28: 170-3.

[43] Keshvari A, Najafi I, Jafari-Javid M, Yunesian M, Chaman R, Taromlou MN, Laparoscopic peritoneal dialysis catheter implantation using a Tenckhoff trocar under local anesthesia with nitrous oxide gas insufflation. Am J Surg 2009; 197: 8-13.

[44] Wong S, Chu K, Cheuk A, et al. Prophylaxis against gram-positive organisms causing exit-site infection and peritonitis in continuous ambulatory peritoneal dialysis patients by applying mupirocin ointment at the catheter exit site. Perit Dial Int 2003; 23: S153-S8.

[45] Bernardini J, Bender F, Florio T, et al. Randomized double-blind trial of antibiotic exit site cream for prevention of exit site infection in peritoneal dialysis patients, 2005. J Am Soc Nephrol 16: 539-45.

[46] Twardowski ZJ, Prowant BF, Nichols WK, Nolph KD, Khanna R. Sixyear experience with swan neck presternal peritoneal dialysis catheter. Perit Dial Int 18:598-602, 1998

[47] Santos CR, Branco PQ, Martinho A, et al. Salvage of malpositioned and malfunctioning peritoneal dialysis catheters by manipulation with a modified Malecot introducer. Semin Dial 2010; 23: 95-9.

[48] Crabtree JH. Fluoroscopic placement of peritoneal dialysis catheters: a harvest of the low-hanging fruits. Perit Dial Int 2008; 28: 134-7. 